\title{
Demand-Side Management System for Autonomous DC Microgrid for Building
}

\author{
Rajeev Kumar Chauhan ${ }^{1}$. C. Phurailatpam ${ }^{1}$ - B. S. Rajpurohit ${ }^{1}$. \\ F. M. Gonzalez-Longatt ${ }^{2} \cdot$ S. N. Singh ${ }^{3}$
}

Received: 2 November 2016 / Accepted: 17 February 2017 / Published online: 28 February 2017

(c) Springer Science+Business Media Singapore 2017

\begin{abstract}
This paper proposes a new demand-side management (DSM) scheme for the autonomous DC microgrid for the future building. The DC distribution system is considered as a prospective system due to the increase of DC loads and DC power sources such as photovoltaic (PV), and battery bank (BB). The BB responds to the changes in a power imbalance between PV generation and demand within an autonomous DC microgrid. The power loss during charging/discharging of the battery is the great challenge for the autonomous DC microgrid supplied by PV. It decreases the system efficiency. The control objective of the proposed DSM scheme is to use the PV energy more efficiently. The proposed control algorithm shifts the deferrable load from non-sunny hours to sunny hours and decreases the building demand during non-sunny hours. In this way it decreases the
\end{abstract}

Rajeev Kumar Chauhan

rajeevchr_nitj@yahoo.com

C. Phurailatpam

chitaranjanph@gmail.com

B. S. Rajpurohit

bsr@iitmandi.ac.in

F. Gonzalez-Longatt

f.gonzalez-longatt@lboro.ac.uk

S. N. Singh

snsingh@iitk.ac.in

1 School of Computing and Electrical Engineering, Indian Institute of Technology Mandi, Mandi 175001, India

2 Department of Electrical and Systems Engineering, Loughborough University, Loughborough, UK

3 Department of Electrical Engineering, Indian Institute of Technology Kanpur, Kanpur, India charging/discharging cycles of the batteries. This is reducing the power losses in the battery and improves system efficiency. The proposed scheme reduces the size of the PV plant, storage and capital cost of the system. The results showing a clear shifting of the load so that to get significant reduction in the system cost which is given numerically as percentatge saving.

Keywords Autonomous DC microgrid - Demand-side management $\cdot$ Photovoltaic $\cdot$ Appliance scheduling $\cdot$ Load balancing

\section{Introduction}

Due to the raise in lifestyle facilities, the energy demand is rapidly increasing. The overall electrification rate in India is $64.5 \%$ and the $35.5 \%$ of the population still lives without access to the electricity [1]. India has focused on solar photovoltaic (PV) power and has a vision of $50 \%$ electricity from renewable energy sources (RESs) by 2030 [2]. The rooftop PV systems for homes are subsidy by the government of India under Jawaharlal Nehru national solar mission (JNNSM) program to achieve the set target of power generation from the RES. The microgrids have become a more attractive option for rural electrification compared with the extension of electrical transmission infrastructure to connect rural areas to the centralized grid [3]. This concept easily works in both the AC and DC domain, but the implementation of the DC microgrid system provides several advantages in terms of redundancy, modularity, fault tolerance, efficiency, reliability, maintenance, size, and design cost. Beside from reducing resource and financial costs, an important advantage of DC microgrid is that it simplifies and provides the opportunity to integrate the RESs such as 
PV, which is intrinsically DC source at higher efficiency. Additionally, with the rapid development of the DC technologies, the DC loads are continuously increasing in the residential and commercial building [4].

A DC microgrid is a system to directly connect the PV system and DC loads. This approach reduces the converter stages and improves the system efficiency [5]. The variability of the power production of $\mathrm{PV}$ systems and stochastic nature of energy demand by loads forces to use indispensable energy storage devices with the optimal size [6] in DC microgrid to smooth the power flow and provide high-quality electric power. The use of battery bank energy storage (BBES) systems is a popular alternative to maximize penetration level of variable power coming from PV into DC microgrid. The optimal operation of DC microgrid requires proper control strategies to control the power sources. The battery control and monitoring system (BCMS) is one of them. The BCMS monitors critical BB conditions and allows an early detection of potential blackout conditions [7]. It implies that the monitoring system of each source can play an important role in system reliability and security of the DC microgrid. The batteries have approximately $85 \%$ efficiency. The minimum use of the battery can improve the system efficiency. The demand side management (DSM) can help to achieve this goal by the load scheduling as per PV generation.

The DSM programs are implemented by the utility companies to control the energy consumption at the customer side [8]. The main task of the DSM is to change the use of load quantitatively by implementating and planning for the utility or monitoring the consumer activities of load utilization. The load management and consumer side local generation are other tasks of the DSMs [9]. The DSM approaches are employed to use the available energy efficiently without installing new infrastructure for generation and transmission [10]. The decentralised DSM mechanism to defragment home loads is based on grid prices and utility companies which are offering the incentives to use the devices optimally [11]. The heuristic based evolutionary algorithm is used for day-ahead load shifting to reduce the peak demand and reshape demand curve [12]. The DSM promotes distributed generation in order to avoid longdistance transport. The DSM facilitates the consumption of locally generated energy immediately whenever it is available for local loads [13]. The main advantage of DSM, is that it is less expensive to intelligently influence a load [14].

Many DSM techniques have been reported in the literature during the last decades. Some of them are based on a neural network approach inspired controllers [15], peak clipping [16], price based DSM to assessing the impacts of timely use tariffs based on demand and peak demand of the residential building [17], direct load control [18] and impact of DSM in the penetration of renewable energy [19].
This paper proposed a new DSM scheme for the autonomous DC microgrid of residential building. The most obvious features such as load scheduling of the deferrable load from non sunny to sunny hours for directly utilize the PV power, and approaching the desired state of charge (SOC) by controlling the cycle based load and other controllable load makes it more advance. The DSM scheme decreases the use of battery power. In other words, it reduces the charging/discharging cycles of the battery bank. The outcomes of the DSM scheme are (i) it reduces the power losses in the battery (i.e. improves the system efficiency), (ii) it reduces the size of the battery bank and PV plant, (iii) it also decreases the capital cost of the system, (iv) It also decreases the peak demand of the building.

\section{Analysis of AC Vs. DC Microgrid}

The converter stage, energy demand and size of power sources (battery and PV plant) are considered in this study for comparative analysis of the AC and DC microgrid.

\section{Appliances}

The energy saving with the DC compatible technology as compared to the AC technology can be found in Table 1. It can be seen from Table 1 that the total energy saving with most of the residential loads is up to $71 \%$. Whereas the rectifiers losses have existed in some cases like refrigerator, dishwasher, washing machine, fans, etc.

\section{Converter Stages}

The DC loads in the residential as well as commercial building are increasing due to the high efficiency of the DC load as compared to the AC compatible load. It forced to connect the AC-DC converters in case of the traditional distribution system (AC system) to supply the DC loads [2]. These conversion stages at the load end are one of the causes to decrease the system efficiency and increase the system cost. The details of the conversion stages with AC system in an autonomous DC microgrid for residential building can be found in Table 2.

\section{Energy Demand}

The AC microgrid energy $\left(E_{d, a c}\right)$ demand consists of the energy consumption in the appliances, and total energy losses $\left(E_{\text {loss }, t}\right)$.

$E_{d}=\sum_{t=1, j=1}^{T, n_{a}} P_{a j}(t) \tau_{h}+E_{l o s s, t}$ 
Table 1 Energy Saving from Efficient DC Internal Technology

\begin{tabular}{lll}
\hline Appliances & Efficient DC Compatible Replacement Technology & Total Energy Savings \\
\hline Fan & $\begin{array}{l}\text { Run by brushless DC motor in place of single-phase AC } \\
\text { induction motors. }\end{array}$ & $47 \%$ \\
$\begin{array}{l}\text { Room air } \\
\text { Vonditioners }\end{array}$ & Variable-speed compressor & $35 \%$ \\
$\begin{array}{l}\text { Lighting- } \\
\text { incandescent }\end{array}$ & 14LPW incandescent goes to CFL (electronic ballast) at 52LPW & $73 \%$ \\
$\begin{array}{l}\text { Lighting- } \\
\text { reflector }\end{array}$ & 15LPW goes to CFL (electronic ballast) at 52LPW \\
$\begin{array}{l}\text { Lighting- } \\
\text { touchier }\end{array}$ & $\begin{array}{l}\text { Assuming } 80 \% \text { incandescent at14 LPW goes to CFL at 52 LPW } \\
\text { Electric geyser } 20 \% \text { CFL stays the same }\end{array}$ & $71 \%$ \\
Refrigerators & Heat pump & $69 \%$ \\
Assuming $85 \%$ standard-size at 587 kWh AEU with savings of \\
$\begin{array}{l}\text { Washing } \\
\text { machine } \\
\text { Ceiling fans }\end{array}$ & BDCPM variable speed & $53 \%$ \\
\hline
\end{tabular}

where $P_{a j}$ is the power consumption in $j^{\text {th }}$ appliance, $n_{a}$ is the number of appliances; $T$ is the scheduling horizon of the optimization; $\tau_{h}$ is the optimize time step $1 \mathrm{~min}$.

The total energy loss consists of the energy losses in the converters $\left(E_{\text {loss }, c}\right)$, line and energy loss $\left(E_{l o s s, b}\right)$ in the battery during charging and discharging due to chemical reactions in the battery. As the system is a prototype and the cable length is very small, therefore, the line losses are considered negligible. The total energy losses $\left(E_{\text {loss }, a c}\right)$ in the autonomous microgrid with the AC distribution system can be expressed as:

$E_{l o s s, t}=\sum_{t=1, j=1}^{T, n_{c}} P_{l o s s, c j}(t) \tau_{h}+P_{l o s s, b}(t) \tau_{h}$

where $n_{c}=\left(n_{a}+n_{s}\right)$ is the number of converters in the autonomous microgrid; $n_{s}$ is the number of sources.
The autonomous microgrid consists of only DC power sources such as PV, BB and the DC loads. Therefore, the total energy demand of the microgrid with the DC distribution system includes the energy consumption in the appliances and energy losses in the battery. The energy consumption can be expressed as:

$E_{d, d c}=\sum_{t=1, j=1}^{T, n_{a}} P_{a j}(t) \tau_{h}+E_{l o s s, b}$

\section{PV and Battery}

PV Size The PV watt-hours needed per day is the combination of the total power consumption in the appliances and power losses in the system. The size of the PV plant depends on the watt-hours needed from the PV plant and number of

Table 2 Description of Cost and Efficiency of Internal Converters in Appliances and Power Sources

\begin{tabular}{|c|c|c|c|c|c|c|}
\hline \multirow[t]{2}{*}{ Source } & \multicolumn{6}{|c|}{ Traditional AC System } \\
\hline & Power & Type of Converters & Efficiency $(\%)[1]$ & Number & Price (Rupees) & Total Cost (Rupees) \\
\hline PV plant & DC & $\mathrm{DC}-\mathrm{AC}$ & 89 & 1 & 7000 & 7000 \\
\hline Battery & DC & AC-DC-AC & 83 & 1 & 7000 & 7000 \\
\hline \multicolumn{7}{|l|}{ Loads } \\
\hline LED bulbs & DC & AC-DC & 84 & 5 & 50 & 250 \\
\hline Tube lights & DC & AC-DC & 84 & 5 & 50 & 250 \\
\hline Fans & DC & AC-DC & 85 & 3 & 150 & 450 \\
\hline Pump & DC & AC-DC & 85 & 1 & 450 & 450 \\
\hline Washing machine & DC & AC-DC & 85 & 1 & 450 & 450 \\
\hline Refrigerator & DC & AC-DC & 85 & 1 & 450 & 450 \\
\hline \multicolumn{6}{|c|}{ Total Converters Cost (Rupees) } & 16,300 \\
\hline
\end{tabular}


average sun hours per day in whole year [20] and can be expressed as:

PV Plant Size $=\frac{P V \text { watt }- \text { hours needed per day }}{\text { Avg. sun hours per day in year }}$

Battery Capacity The battery size should be large enough to store the sufficient energy to supply the load in the nonsunny hours and cloudy days.

Battery capacity $\left(\mu_{\mathrm{n}}\right)=\frac{\mathrm{k}_{\mathrm{a}}}{\eta_{\mathrm{b}} \times D O D_{b} \times \mathrm{V}_{\mathrm{nl}}} \times n_{a u}$

where $k_{a}$ is the watt-hours needed for appliances per day, $\eta_{b}$ is the battery efficiency $(0.85) ; D O D_{b}$ is the depth of discharge $(0.5) ; V_{n l}$ nominal voltage of battery; $n_{a u}$ is the number of autonomy ( 2 day), average winter temperature $80^{\circ} \mathrm{F}$.

\section{State of Charge of Battery Bank}

In general, the state of charge (SOC) of the battery is the ratio of its present capacity $(\mu(\mathrm{t}))$ to the nominal capacity $\left(\mu_{n}\right)$ of the battery [21]. The SOC can be defined as:

$\operatorname{SOC}(t)=\frac{\mu(t)}{\mu_{n}}$

The coulomb counting method measures the charging/ discharging current of a battery and integrates the charging /discharging current over time in order to estimate SOC [21]. The SOC can be calculated as:

$\operatorname{SOC}(t)=\operatorname{SOC}(t-1)+\frac{i(t)}{\mu_{n}} \Delta t$

\section{Autonomous DC Microgrid Configuration}

The conceptual layout of the autonomous prototype DC microgrid for the residential building is shown in Fig. 1 and its hardware setup is shown in Fig. 2. Two solar charge controllers (SCCs) are connected in parallel to supply the load of the prototype DC microgrid. Additionally, both the SCCs connects to the energy storage (ES), which consists of four battery banks (BBs) BB-1, BB-2, BB-3 and BB-4 in parallel to store the surplus energy or balance the surplus demand. These types of connections for the BB increase the reliability of the DC microgrid. For example the PV plant of the SCC-1 is in outage then the SCC-1 connects their load to the ES and SCC- 2 via 12 V DC bus between both the SCCs to feed the surplus energy to the ES. The voltage and state of charge (SOC) of the batteries are monitored in real time, which give the energy stored in the batteries. It helps to find out the battery back-up period to supply the future demand.
The current sensors CS-1 and CS-2 are mounted in the service mains of PV-1 and PV-2 to monitor the PV currents injected to the controllers, while The current sensors CS-3 and CS-4 mounted on the battery terminals of the SCC-1 and SCC-2 to monitor the currents of ES shares with SCC1 and SCC-2, respectively. The load on both the controllers are supplied separately and monitored by the current sensors CS-5 and CS-6, respectively. All the sensors are connected to the micro-controller (Arduino Mega) and retrieve the values at every one minute. The electronics switches $S_{1}-S_{16}$ are used to automatically switch 'ON'/'OFF' the building load. The microcontroller executes the control algorithm and creates the digital control signal in the form of ' 0 ' and ' 1 ' to actuate the electronic switch to turn ' $\mathrm{ON}$ '/'OFF' their respective appliance. The details of the load and their location in the building can be found in the Table 3. The technical specifications of the system components can be found in Table 4.

\section{Demand-Side Management Algorithm}

The flow chart of the proposed control algorithm for the demand-side management system is shown in Fig. 3. The $\mathrm{PV}$ feed the maximum power to the microgrid irrespective of the demand at different time instants. The monitoring of the PV generation, load and storage is done. The control objective of the DSM scheme is to maximize the direct use of PV power and maintain the SOC of the battery bank to supply the future load of the building. Therefore the proposed scheme schedules the deferrable loads (washing machine and pump) in this manner so that they operate directly by the PV power without affecting the consumer comfort. This reduces the charging/discharging of the battery and improves the efficiency of DC microgrid. The controllable loads such as tube lights are switched 'OFF' and the refrigerator operates with the 'control cycle' mode to reduce the building demand and increase the charging or decrease the discharging of the battery bank to achieve the desired SOC as soon as possible. The desired SOC shows the minimum requirement of stored energy in the battery to supply the future load during PV outage or generates a small amount of power as compare to the load. The proposed DSM scheme is explained in more detail by the following discussion.

When PV acts as an outage source and battery supplies the load, therefore, the SOC level of the BB decrease at every time instant. As the battery SOC deficits from the desired level, the critical loads (i.e. LED bulbs and fans) remains ' $\mathrm{ON}$ ' and refrigerator operates with 'control cycle' (i.e it remains switch 'ON' for 15 minutes instead of $30 \mathrm{~min}$ utes and it remains switch 'OFF' for 80 minutes in a cycle). Besides that other, the load gets switched 'OFF'. In this way, 


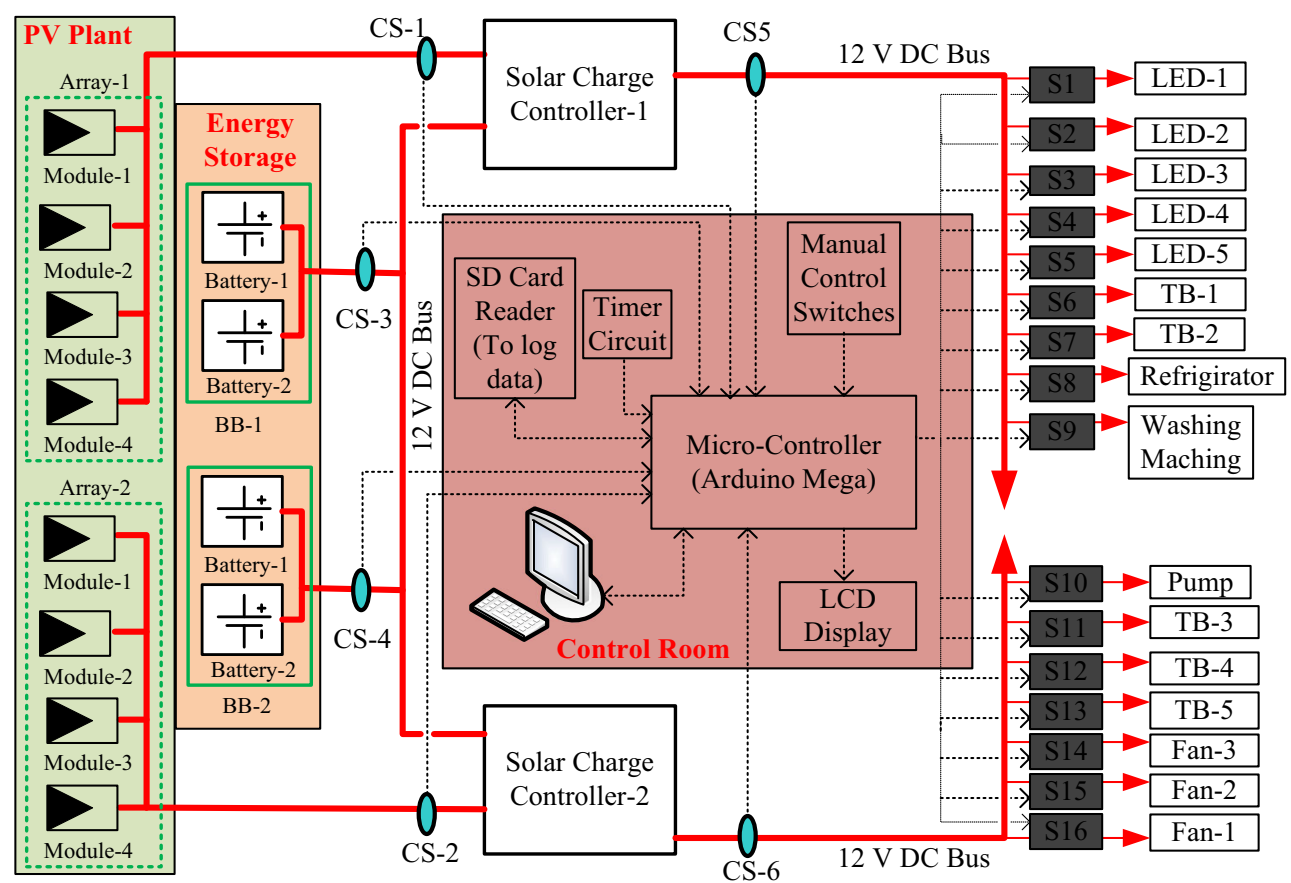

Fig. 1 Conceptual diagram of the proposed DC microgrid

the discharging rate of the battery bank is decreased and battery maintained its desired SOC. When the PV starts generation and the battery SOC is less than its desired level than battery start charging. The surplus PV generation supplies the building load. If the PV surplus generation is less than the building demand besides that the difference of desired time $\left(t_{d}\right)$ and appliance 'ON' time $\left(t_{r}\right)$ is greater than or equal to the difference of termination of task $\left(t_{t c}\right)$ and decision instant $\left(t_{d i}\right)$ than the deferrable load is ' $\mathrm{ON}$ ' while the refrigerator operates with 'control cycle' and other non critical loads gets switched 'OFF'. The priority of the deferrable load is based on the desired 'ON' time of the loads to complete the task. For example, at the time instant 10:00 hrs, the PV plants produce approximately 90 watts of the surplus power, which activates the controller to switch 'ON' the deferrable load. While the status of the deferrable loads is as; the washing machine (70 watts) should run for 90 minutes up to 13:00 hrs to wash the cloth as per the consumer

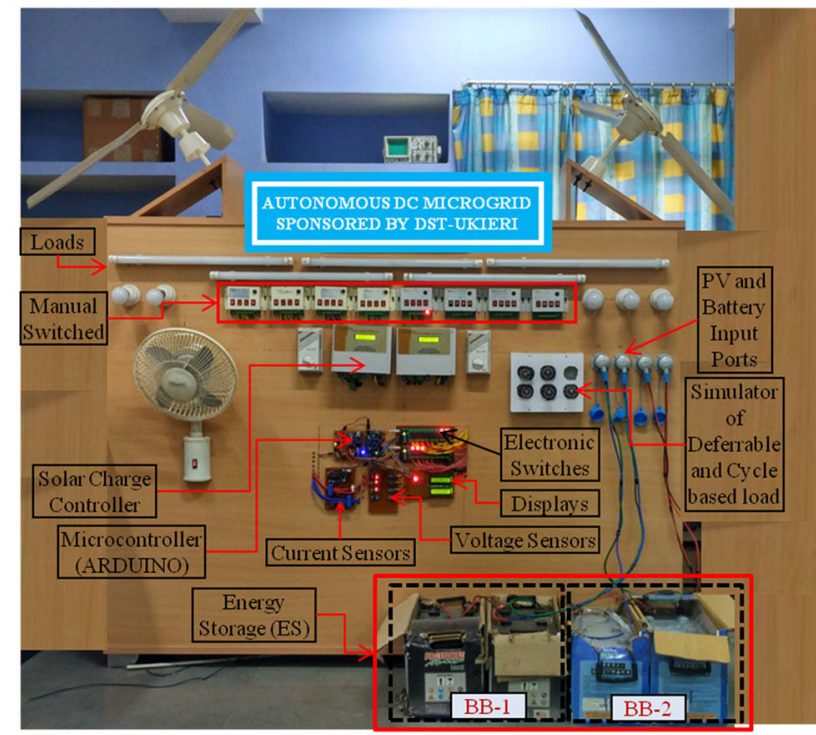

(a) Microgrid Hardware setup

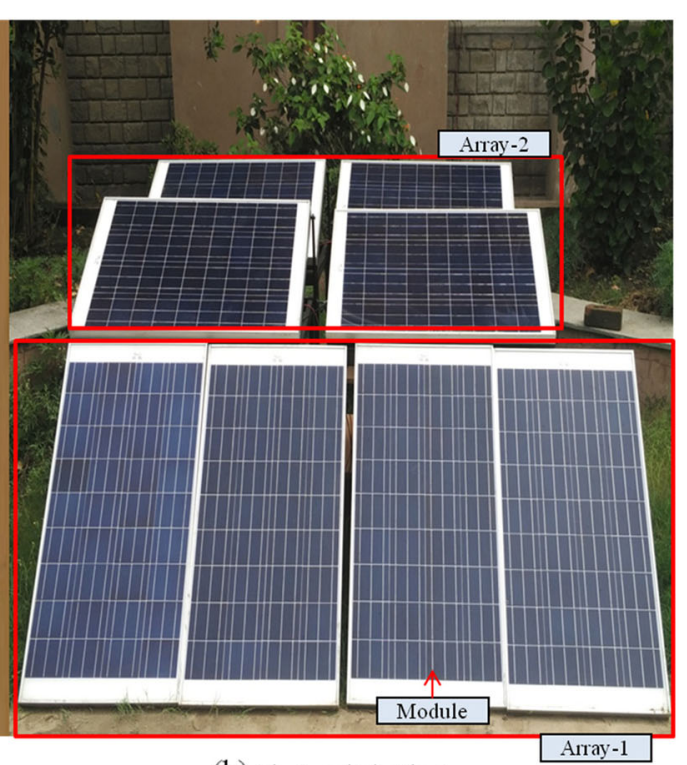

(b) Photovoltaic Plant

Fig. 2 Experiential Setup of DC microgrid (a) Controller, Load and battery Bank, (b) Photovoltaic plant 
Table 3 Load Locations in the Building

\begin{tabular}{llllllll}
\hline Location & \multicolumn{2}{l}{ Controllable Load } & & & & \multicolumn{2}{l}{ Deferrable Load } \\
\cline { 2 - 5 } \cline { 7 - 8 } & Fan & Tube Light & LED & Refrigerator & & Washing Machine & Pump \\
\hline Kitchen & & $\sqrt{ }$ & $\sqrt{ }$ & $\sqrt{ }$ & & - & - \\
Bed Room-1 & $\sqrt{ }$ & $\sqrt{ }$ & $\sqrt{ }$ & - & - & - \\
Bed Room-2 & $\sqrt{ }$ & $\sqrt{ }$ & $\sqrt{ }$ & - & & - & - \\
Living Room & $\sqrt{ }$ & $\sqrt{ }$ & $\sqrt{ }$ & - & & - & $\sqrt{ }$ \\
Bath Room & - & - & $\sqrt{n}$ & - & & $\sqrt{ }$ & - \\
Balcony & - & $\sqrt{ }$ & - & - & & - & - \\
\hline
\end{tabular}

desires (instructions), and pump (80 watts) must run for 30 minutes to $10: 50 \mathrm{hrs}$. The difference of the decision time instant and task terminations time instants are 180 minutes and 50 minutes for washing machine and pump, respectively. It verifies that the pump has more priority than the washing machine, therefore pump gets switched 'ON'.

When the PV generation is greater than the building demand (i.e. demand of critical and non critical loads including with deferrable loads) and the decision instant belongs to the task slot of the deferrable load its task is not completed therefore the deferrable load remain 'ON' and the surplus PV power feed to the battery. On the other hand, if the decision instant does not belong to the task slot of the deferrable load then it remains switch 'OFF'.

\section{Results}

The actual hardware of an autonomous DC microgrid has been built to validate the feasibility of the proposed demandside management (DSM) scheme for the autonomous DC microgrid of the building. The photovoltaic (PV), battery bank (BB) and load are connected to the unipolar DC distribution system. The two solar charge controllers (SCCs) are connected in parallel to connect the PV plant with the DC microgrid. The SCCs has three terminals to connect with the PV plant, battery, and load. The BB terminals of both the SCCs are connected to each other via BB bus. This type of connection between $\mathrm{BB}$ terminals connects the batteries in parallel and provides the common point of connection to both the SCCs to connect with the BB. The beauty of these connections is that the BB can store the surplus power of both the SCCs and supply their surplus demand. The DC bus Power can be expressed as:

$\sum_{j=1}^{n_{a}} P_{a j}(t)=\sum_{j=1}^{n_{p v}} P_{p v j}(t) \pm \sum_{j=1}^{n_{b}} P_{b b j}(t)$

where $P_{b b j}$ is the power of $j^{t h}$ battery and $n_{b}$ is the number of batteries, $P_{p v j}$ is the power of $j^{t h} \mathrm{PV}$ array and $n_{p v}$ is the number of PV arrays, $P_{a j}$ is the power consumption in $j^{t h}$ appliance and $n_{a}$ is the number of appliances.

In this paper the DSM scheme is compared with the conventional scheme. In the conventional scheme, there is no feedback to switch 'ON' and 'OFF' the appliances (i.e. without demand side management). Therefore, the deferrable load does not shift their operating time from non sunny hours to sunny hours while the cycle based load operates in the regular cycle mode. The building demand curve with the conventional scheme, proposed DSM scheme, and the PV power generation for a typical day are shown in Fig. 4.
Table 4 Parameters of Microgrid Components

\begin{tabular}{llll}
\hline Components & Specifications & Quantity & Total Power \\
\hline PV & $\mathrm{I}_{\mathrm{sc}}=5.95 \mathrm{~A}, \mathrm{~V}_{\mathrm{oc}}=22.95 \mathrm{~V}$, Power $=100 \mathrm{~W}$ & 8 & $800 \mathrm{watt}$ \\
Battery & $12 \mathrm{~V} 150 \mathrm{Ah}, \mathrm{C} 20$ & 4 & $600 \mathrm{Ah}$ \\
Solar Charge Controller & $12 \mathrm{~V}, 40 \mathrm{~A}$ & 2 & \\
Connecting load & & & \\
Fan & $12 \mathrm{~V}, 30$ watt & 3 & 90 watt \\
LED bulb & $12 \mathrm{~V}, 5$ watt & 5 & 25 watt \\
Tube light & $12 \mathrm{~V}, 8$ watt & 5 & 40 watt \\
Refrigerator & $12 \mathrm{~V}, 60$ watt & 1 & 60 watt \\
Washing machine & $12 \mathrm{~V}, 80$ watt & 1 & 80 watt \\
Water pump & $12 \mathrm{~V}, 80$ watt & 1 & 80 watt \\
\hline
\end{tabular}


Fig. 3 Flowchart of control algorithm for demand management
Read/Input

Desired 'ON' time (td), measured 'ON' time ( $\left.\mathrm{tr}_{\mathrm{r}}\right)$, building load $(\mathrm{Pbl})$, PV generation $\left(\mathrm{P}_{\mathrm{pv}}\right)$, Battery desired $\left(\mathrm{SOC}_{\mathrm{d}}\right)$ and measured $\left(\mathrm{SOC}_{\mathrm{m}}\right)$, upper $\mathrm{SOC}$ limit $\left(\mathrm{SOC}_{\max }\right)$,

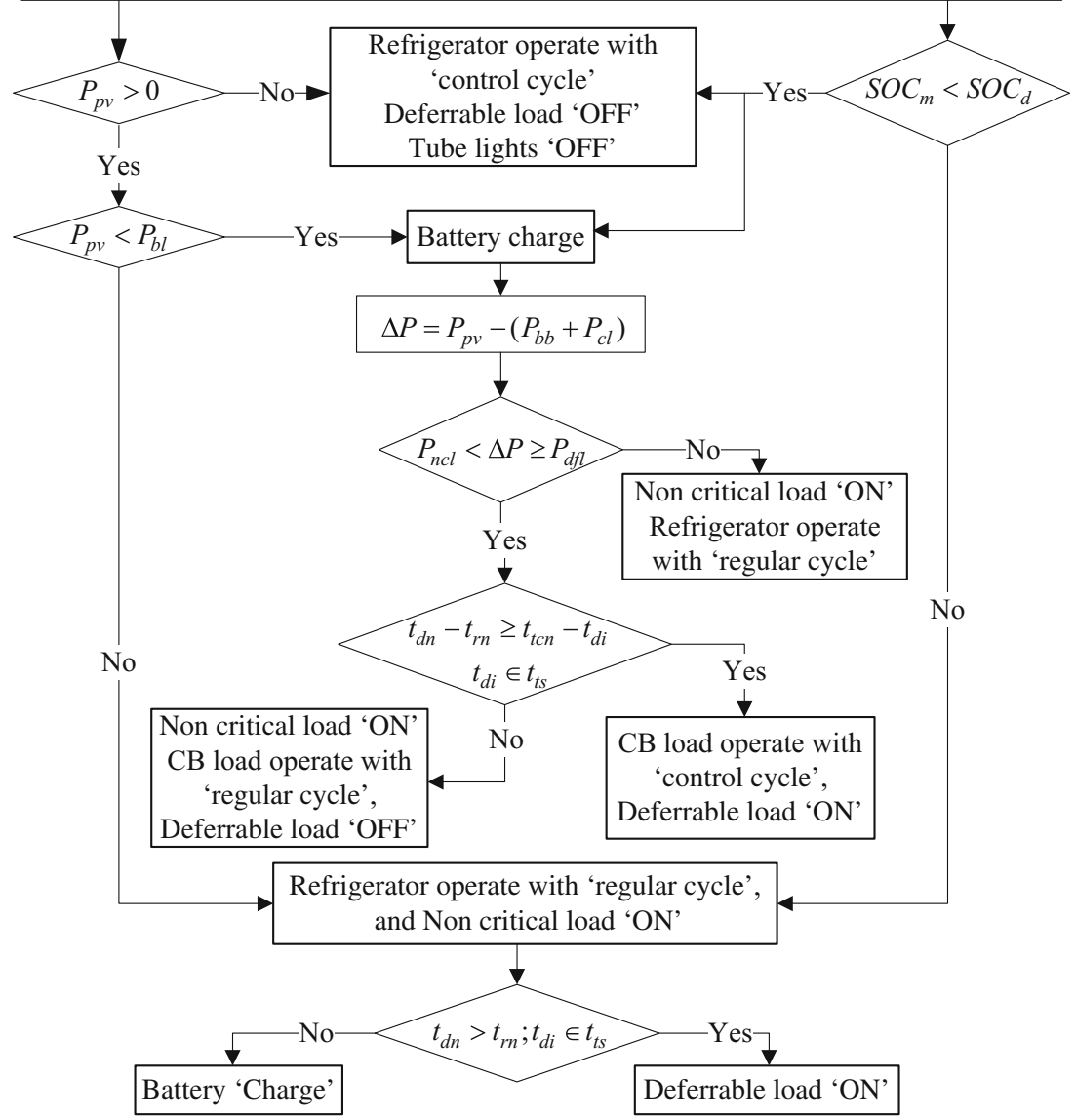

The peak demand of the building is 297 watts and 285 watts with a conventional scheme and proposed DSM scheme, respectively. The building peak demand with the conventional scheme is 297 watt during 7:21-7:30 hrs time interval (non-sunny period) and it is supplied by the battery, while the proposed DSM scheme reduces the building demand upto 215 watts in this time interval because the deferrable load water pump has been switched 'OFF'. In the sunny hours, the building peak demand with the proposed DSM scheme is 285 watt during 17:47-17:50 hrs,

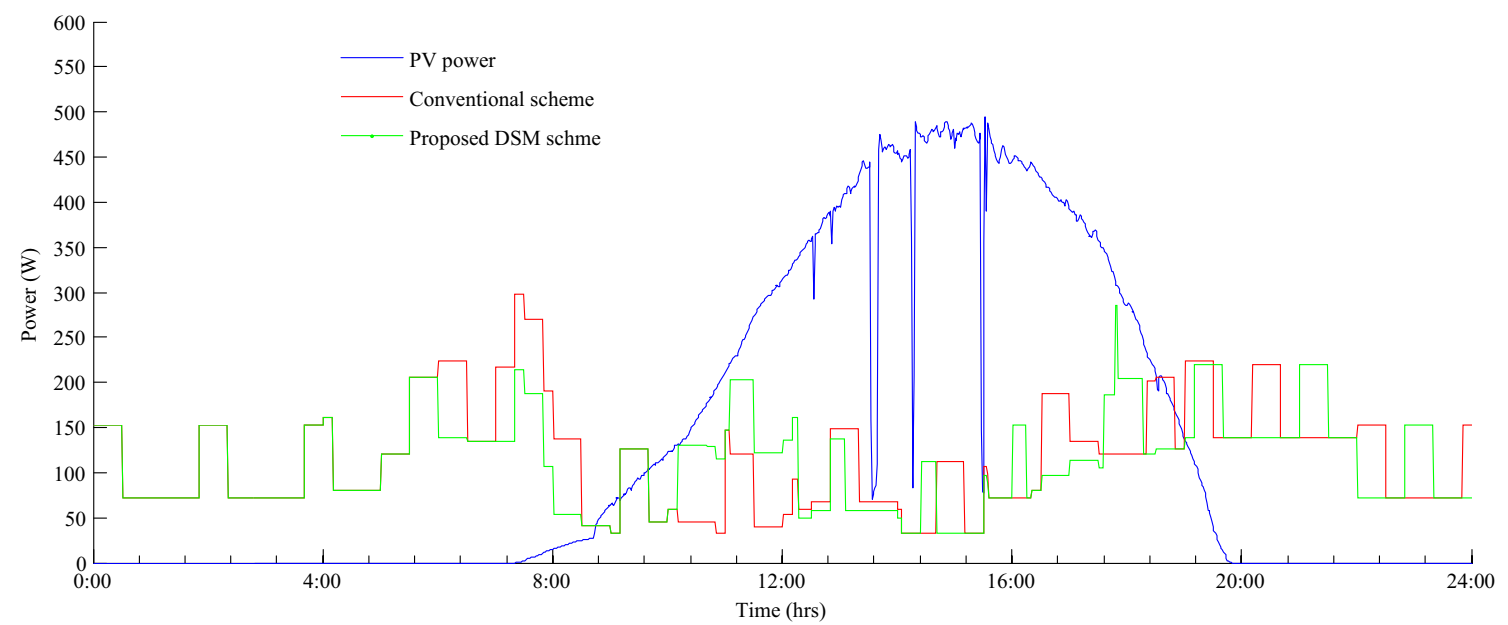

Fig. 4 Power curve of PV generation and building demand with conventional scheme and proposed DSM scheme 
while the building peak demand with conventional scheme is 120 watt during 17:30-18:20 hrs. The proposed DSM scheme has a lower demand as compared to the conventional scheme during the PV act as outage source or PV generation is less than the building demand and the load are supplied by the battery. It verifies that the proposed DSM scheme shifts the building demand from non-sunny hours to sunny hours. The DSM scheme also reduces the BB charging/discharging power (rate) as compareed to the conventional scheme as shown in Fig. 5. This is the one cause of battery heating, poor health and short life [5]. It verifies that the proposed DSM scheme keeps the battery cool, healthy and increase their life as compared to the conventional scheme.

\section{Mode I: Battery as Source (Regular Operation)}

The state of charge (SOC) of the battery gives the information about the energy stored in the battery to supply future load. The desired SOC of the battery represents the minimum energy required to supply the load. At the starting of the day, at time instant 0:00 the desired SOC level is $49.5 \%$ to supply the future load of the building while both conventional scheme and proposed DSM scheme has $50 \%$ SOC level as shown in Fig. 6. This is the reason, the proposed DSM scheme keeps the load pattern as per the conventional scheme. The battery supplies the same load with conventional and proposed DSM scheme during 0:00-05:59 hrs time interval as shown in Fig. 5.

\section{Mode II: PV and Battery as Source (Deferrable Load Scheduling)}

During early morning, the PV generation is lower than the demand and most of the load is supplied by the battery. For example, at time instant 6:00 hrs, the pump is switched
'ON' with the conventional scheme which is the cause to achieve lower SOC than the desired SOC with the conventional scheme during 6:00-6:30 hrs time interval as shown in Fig. $8 \mathrm{c}$ by the red line. While the pump task completion instant is $10: 50 \mathrm{hrs}$ and operating time to fill the tank is 30 minutes. Therefore, the pump has to run for 30 minutes to complete their task before the 10:50 hrs. The proposed DSM scheme keeps critical and another controllable load (as per Fig. 7) connected as per conventional scheme and waits to switch 'ON' the pump for the time interval in which surplus PV generation is higher than the combination of critical load and pump load. As the PV generation is higher than the critical load of the building at time instant 10:10 hrs the pump is switched 'ON' and remains 'ON' to 10:40 hrs (for $30 \mathrm{~min}$ utes) and the surplus PV power is stored in the battery as shown in Fig. 5.

Similarly, at time instant 7:00 hrs, the washing machine is switched 'ON' with the conventional scheme and remains 'ON' during 7:00-8:30 hrs time interval as shown in Fig. 8b by a red line, which is the cause to achieve lower SOC than the desired SOC with a conventional scheme during 7:008:30 hrs time interval as shown in Fig. 6. While the washing machine task completion time is $12: 30 \mathrm{hrs}$ with 90 minutes the operating time. The proposed DSM scheme keeps the washing machine at the second priority and shifts the washing machine operating time from 7:00-8:30 hrs to the future. As the PV generation at 10:41 hrs becomes higher than the building demand (critical load and deferrable load washing machine), the washing machine is switched 'ON'. At time instant 10:59 hrs, the PV generation becomes lower than the building demand (critical load and deferrable load washing machine) and remain lower upto 11:04 hrs so the washing machine remains switch 'OFF' during 10:59-11:04 hrs while the battery is charged by the surplus power to achieve the BB SOC higher than the desired. As the washing

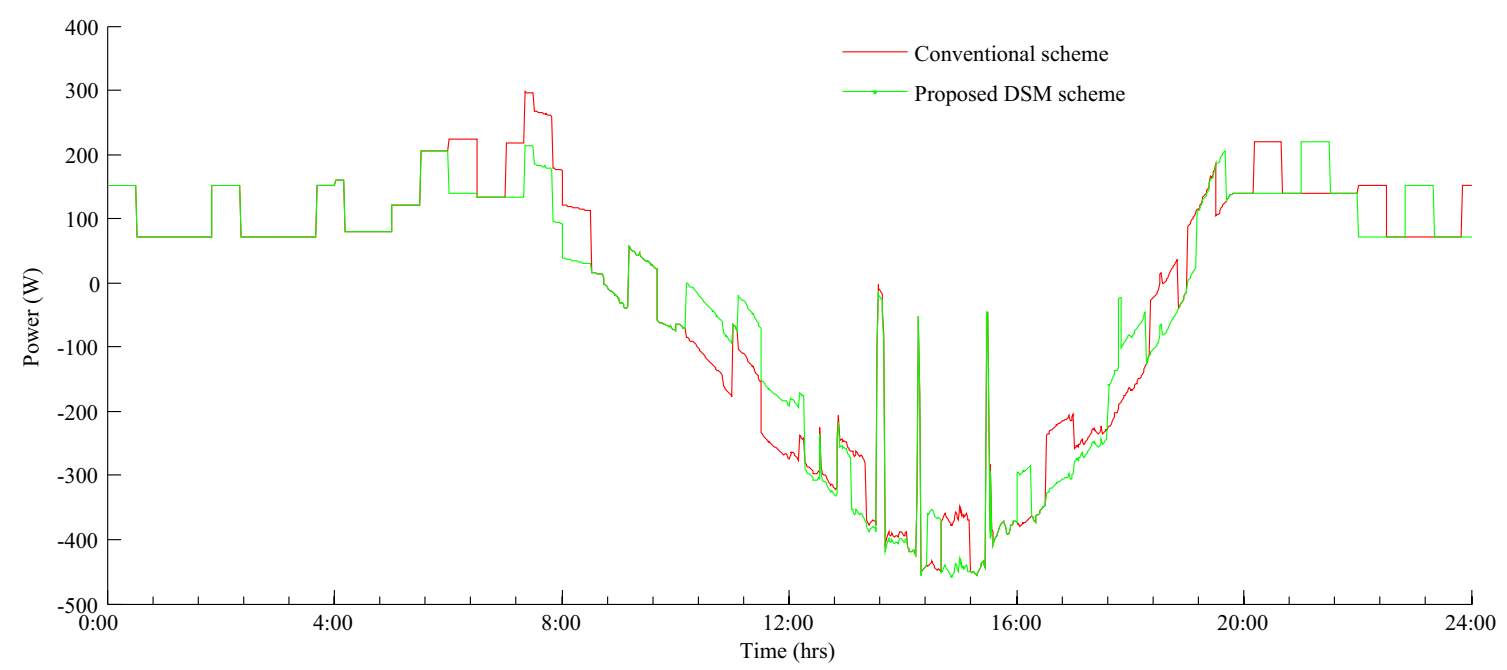

Fig. 5 Battery power sharing with DC microgrid 


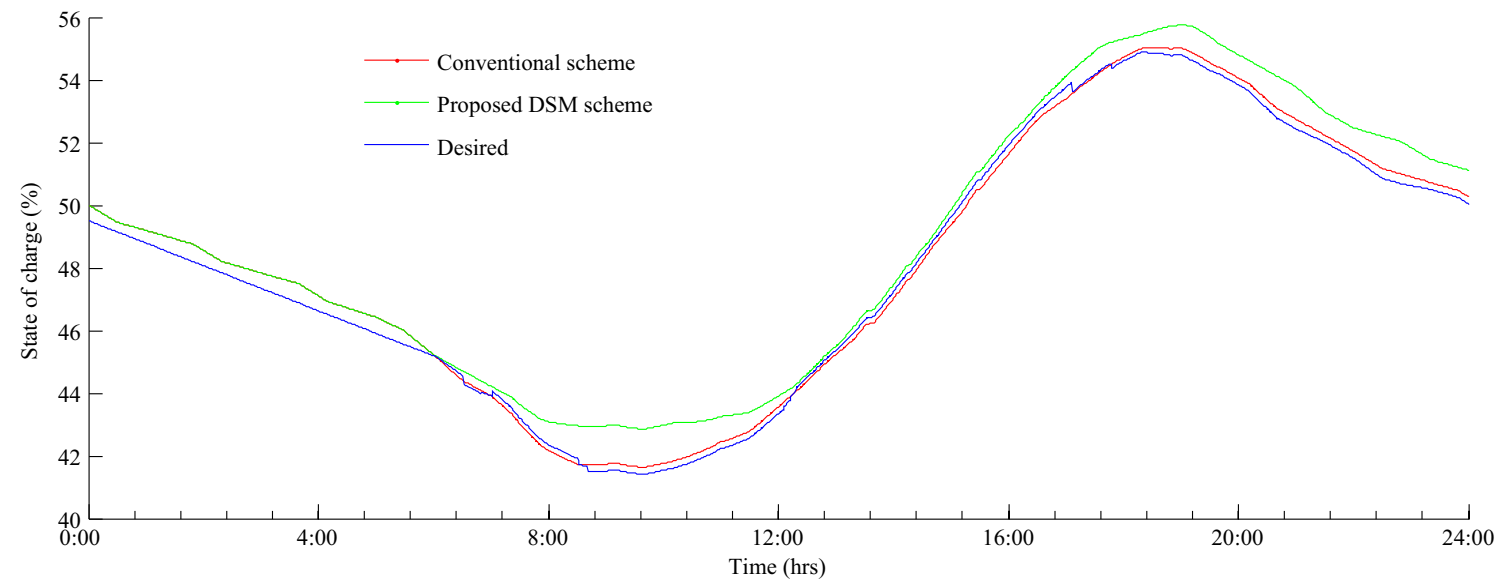

Fig. 6 State of charge of battery bank

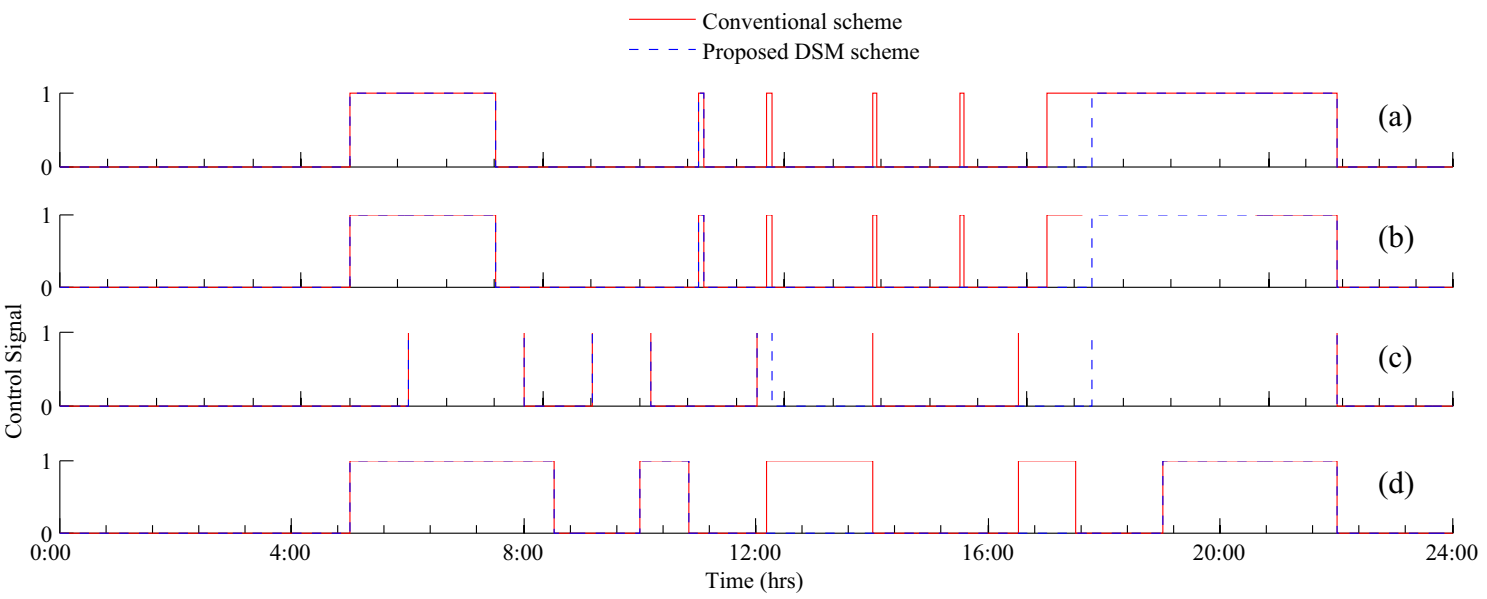

Fig. 7 Controllable load (LED bulb) mounted in (a) bed room-1, (b) bed room-2, (c) living room, (d) kitchen

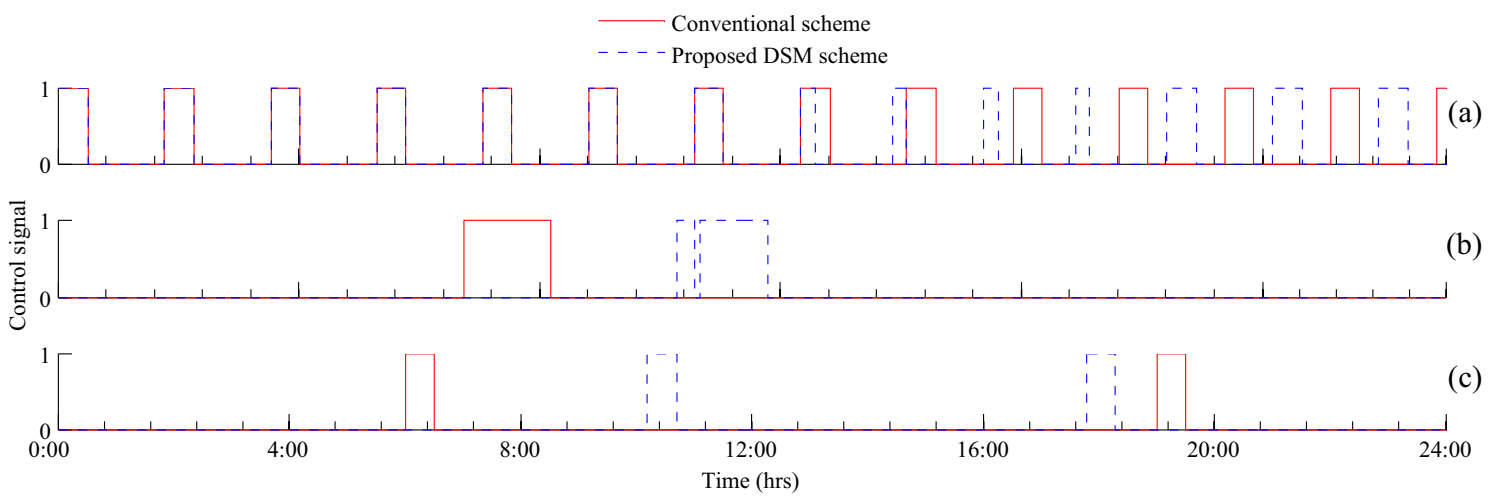

Fig. 8 Control of cycle based and deferrable load (a) refrigerator, (b) washing machine, (c) water pump 
Table 5 Description of PV and Battery Bank and Their Costs

\begin{tabular}{llll}
\hline Source/Load & DCDS & DCDS with DSM & Saving (\%) \\
\hline Building Load is 2.7 kWh (Meter-units/day) & & & \\
Battery bank capacity (AH) & 585 & 434 & $25.81 \%$ \\
Number of Batteries (150 Ah) & 4 & 3 & $25 \%$ \\
Energy needed from PV (kWh) & 1.023 & 0.7 & $31.57 \%$ \\
Noumber of PV modules (100 watt) & 11 & 7 & $36.36 \%$ \\
Cost of PV plant (Rupees) & $1,10,000$ & 70,000 & $36.36 \%$ \\
Cost of battery bank (Rupees) & 54000 & 40500 & $25 \%$ \\
Total System Cost (Rupees) & $1,64,000$ & $1,10,500$ & $32.62 \%$ \\
\hline
\end{tabular}

machine operation time is 90 minutes and it runs only for 18 minutes so it has to be switched 'ON' again to complete the task as the PV generation becomes higher than demand at time instant 11:05 hrs washing machine is switched ' $\mathrm{ON}$ ' and remains 'ON' to 12:18 hrs to complete the task as shown in Fig. $8 \mathrm{~b}$ by blue line.

\section{Mode III: PV with Low SOC of BB (Control of Non-Critical and Cycle Based Load)}

During 12:16-17:40 hrs time interval, the PV generation is greater than the building demand, but the battery SOC is lower than the desired with the conventional scheme. The proposed DSM scheme reduces the building demand by switching 'OFF' the controllable loads (LED bulbs mounted in bedroom-1, bedroom-2, living room and kitchen as shown in Fig. 7a, b, c and d by blue lines), and cycle based load (refrigerator) operate with the control cycle mode (i.e it remains switch 'ON' for 15 minutes instead of 30 minutes) as shown in Fig. 8a by a blue line.

\section{Mode IV: PV and SOC Higher (Pre-Scheduling of Deferrable load)}

During 17:41-18:10 hrs time interval, the PV generation is higher than the building demand (demand with a conventional scheme and future deferrable load i.e. pump) and the battery SOC is higher than the desired. Additionally, the task starts and completion time limit (evening time) for the pump is $17: 30-19: 30 \mathrm{hrs}$ and the operating time is 30 minutes. The proposed DSM scheme switches 'ON' the pump at the time instant 17:41 and keeps it 'ON' during 17:41-18:10 hrs as shown in Fig. 8c. The surplus PV generation is stored in the battery.

The cost of a power sources for the autonomous DC microgrid can be found in Table 5 with the conventional scheme and demand side management scheme for an energy demand of $2.7 \mathrm{kWh} /$ day. The size of the PV and battery bank are calculated by referring the Eqs. 4 and 5. The testing shows that, customers achieve $32.62 \%$ total system cost saving with the DSM scheme as compared to the conventional scheme. There is $36.36 \%$ savings in the cost of PV source while the saving in battery cost is $25 \%$.

\section{Discussion}

It is clear that the DC microgrid in residential building with DC appliances and renewable energy resources (DC power sources) provides the significant energy efficiency as compared to the traditional AC system. There are many challenges to be addressed for implementation of the demand-side management system in real time. One challenge is the monitoring of the energy level in the battery at every time instant. The open circuit voltage based state of charge (SOC) (i.e battery energy level) estimating scheme is required 3-4 hours rest time to monitor the SOC of the battery which is not possible in real-time applications. The proposed scheme monitors the SOC using coulomb counting method because of its simplicity and accuracy.

Other challenges are the availability of the hardware components in the market and their cost is another challenge. The cost of the DC appliances is not standardized. To achieve the battery SOC at the desired or higher level and shifting the deferrable load to the sunny hours are the great challenge in autonomous DC microgrid. The inclusion of the control to the controllable loads such as LED bulbs and cycle base load (refrigerator) makes it more robust and reliable in case of sunny as well as in the case of non-sunny hours. The proposed DSM scheme utilizes the PV energy in a very smart way and makes it more energy efficient.

\section{Conclusions}

This paper has presented a demand-side management (DSM) scheme for the autonomous DC microgrid of a residential building. The appliances have been automatically 
switching 'ON'/'OFF' as per the control algorithm. The performance of the DSM scheme has been tested in terms of efficient utilization of the PV energy by scheduling the deferrable load from non-sunny hour to the sunny hours. It also monitors the battery state of charge (SOC) and keeps it close to the desired level. The proposed DSM system switches 'OFF' the controllable appliances (LED bulbs) and shifts the cycle based load (refrigerator) from regular cycle mode to the control cycle mode. The peak demand of the building during sunny and non-sunny hours has also been reduced significantly. The energy exchange band of the battery and the capital cost of the system have been reduced in proposed DSM scheme significantly as compared to the conventional scheme. The proposed scheme can be used for LVDC microgrid such as building with renewable energy resources and data centers.

Acknowledgments Authors are thankful to the DST-UKIERI for financial support

\section{References}

1. Jeyaprabha SB, Selvakumar AI (2015) Optimal sizing of photovoltaic/battery/diesel based hybrid system and optimal tilting of solar array using the artificial intelligence for remote houses in India. Energ Buildings 96:20-52

2. Jhunjhunwala A (2016) Solar-DC: India towards energy independence. Curr Sci 111(3):599-600

3. Savage P, Nordhaus R, Jamieson S (2010) DC microgrids: benefits and barriers. Yale School of Forestry and Environmental Studies. http://environment.yale.edu/publication-series/ documents/downloads/0-9/05-DC-Microgrids.pdf

4. Chauhan RK, Rajpurohit BS, Hebner RE, Singh SN, GonzalezLongatt FM (2016) Voltage Standardization of DC Distribution System for Residential Buildings. J Clean Energ Technol 4(2):167-172

5. Chauhan RK, Rajpurohit BS, Singh SN, Gonzalez-Longatt FM (2016) Intelligent Energy Management System for PV-Batterybased Microgrids in Future DC Homes. Int J Emerg Electr Power Syst 17(1):173-189

6. Jossen A, Garche J, Sauer DU (2004) Operation conditions of batteries in PV applications. Sol Energy 76(5):759-769
7. Hu X, Li S, Peng H, Sun F (2012) Robustness analysis of state of charge estimation methods for two types of li-ion batteries. J Power Sources 217:209-219

8. Reducing electricity consumption in houses Ontario Home Builders' Assoc., May 2006, Energy Conservation Committee Report and Recommendations. http://www.energy.gov/ energysaver/reducing-electricity-use-and-costs

9. Clark Gellings W (1985) The concept of demand-side management for electric utilities. Proc IEEE 73(10):1468-1470

10. Rad AHM, Wong VWS, Jatskevich J, Schober R, Garcia AL (2010) Autonomous demand-side management based on gametheoretic energy consumption scheduling for the future smart grid. IEEE Trans Smart Grid 1(2):320-331

11. Ramchurn SD, Vytelingum P, Rogers A, Jennings N (2011) Agent-based control for decentralised demand side management in the smart grid. In: 10th International Conference on Autonomous Agents and Multi-agent System, 5-12

12. Logenthiran T, Srinivasan D, Shun TZ (2012) Demand side management in smart grid using heuristic optimization. IEEE Trans Smart Grid 3(2): 1244-1252

13. Palensky P, Dietrich D (2011) Demand side management: demand response, intelligent energy systems, and smart loads. IEEE Trans Ind Informatic 7(2):381-388

14. Matallanas E, Castillo-Cagigal M, Gutiérrez A, MonasterioHuelin F, Caamaño-Martín E, Masa D, Jiménez-Leube J (2012) Neural network controller for active demand-side management with PV energy in the residential sector. Appl Energy 91(1):90-97

15. Masters GM (2004) Renewable and efficient electric power systems. NJ: Wiley, Hoboken

16. Torriti J (2012) Price-based demand side management: assessing the impacts of time-of-use tariffs on residential electricity demand and peak shifting in Northern Italy. Energy 44(1):576-583

17. Ruiz N, Cobelo I, Oyarzabal J (2009) A direct load control model for virtual power plant management. IEEE Trans Power Syst 24(1):959-966

18. Pina A, Silva C, Ferrao P (2012) The impact of demand side management strategies in the penetration of renewable electricity. Energy 41(1):128-137

19. Chang WY (2013) The state of charge estimating methods for battery: a review. ISRN Applied Mathematics, 1-7. doi:10.1155/2013/953792

20. Bhoye H, Sharma G (2014) An analysis of one MW photovoltaic solar power plant design. International Journal of Advanced Research in Electrical Electronics, and Instrumentation Engineering 3(1):6969-6973

21. Ng KS, Moo CS, Chen YP, Hsieh YC (2009) Enhanced Coulomb counting method for estimating state-of-charge and state-of-health of lithium-ion batteries. Appl Energy 86(9):1506-1511 